\title{
Cystic kidneys in copper exposed mussels
}

\author{
Inke Sunila
}

Department of Zoology, Division of Physiology, University of Helsinki, Arkadiankatu 7, SF-00100 Helsinki 10, Finland

\begin{abstract}
Mytilus edulis L. were exposed to $0.2 \mathrm{mg} \mathrm{t}^{-1}$ copper for $24 \mathrm{~h}$ in aquaria before being transferred to cages submerged in the sea. The first renal cysts appeared 4 mo after exposure. On average $20 \%$ of the exposed mussels ( 166 of 830 survivors) developed cystic kidney lesions within 1 yr. No cysts were found in control mussels. The cysts were thin walled, fluid filled sacs arising from the kidney epithelium and filling part of the mantle cavity. The cyst wall was composed of 2 cell layers: the inner layer consisting of kidney epithelium which gradually changed to columnar epithelium, and the outer layer of single columnar epithelium which changed to squamous epithelium. Both cell layers were proliferative. The lesions were accompanied by an inflammatory response. The cysts were considered to be dilatations of the kidney tubules due to polypoid tubular obstruction.
\end{abstract}

\section{INTRODUCTION}

Kidneys are the principal site of accumulation of heavy metals in the mussel Mytilus edulis. Metals are immobilized and detoxified in kidney cells by cellular compartmentation into granules which are eventually excreted in the urine (George et al. 1982). The mussel kidney is composed of a tubular structure on both sides of the visceral mass at the base of the gills, one central tubule giving rise to numerous blind ending branches. The kidney tubules are made up of an infolded single layer of columnar epithelium (kidney cells) and are connected to the pericardial cavity through the pericardial funnel and renopericardial canal. Ultrafiltration takes place in the pericardial cavity through the walls of the auricle (Pirie \& George 1979, Yevich 1980).

Cystic kidney lesions have not previously been described in molluscan pathology. In vertebrate pathology, however, renal cysts have been reported in several species. The lesions are either polycystic or single cysts, and are thought to be congenital or acquired. In man, simple cysts are common in elderly patients. These are solitary or multiple acquired abnormalities of undetermined, possibly diverse causes (Walsh et al. 1986). In experimental animals a wide variety of chemical compounds are known to induce renal cysts (Safouch et al. 1970, Dobyan et al. 1981). Drug-induced cysts are considered to originate from tubular obstruction (Goodman et al. 1970) or a structural defect of the tubular basement membranes (Carone et al. 1974).
In long-term tests, copper exposed mussels Mytilus edulis were observed to develop cysts which arose between gills and mantle, and often invaded most of the mantle cavity. This paper reports a high occurrence of cystic kidneys in copper exposed mussels and describes their histopathology.

\section{MATERIAL AND METHODS}

Samples were collected by a diver in the vicinity of the Tvärminne Zoological Station in the Gulf of Finland (Baltic Sea, 29 $51^{\prime} \mathrm{N}, 60^{\circ} 12^{\prime}$ E). Mytilus edulis (2.0 to $3.5 \mathrm{~cm}$ maximum length) were enclosed in cages and exposed to $0.2 \mathrm{mg} \mathrm{l}^{-1}$ copper $\left(\mathrm{CuSO}_{4} \quad 3 \mathrm{H}_{2} \mathrm{O}\right.$ analytical grade, static exposure) in aerated aquaria for $24 \mathrm{~h}$.

Renal cysts were induced in 2 experiments. In the first experiment (August, exposure temperature $20^{\circ} \mathrm{C}$ ), the number of mussels with cystic lesions was counted 4 and 12 mo after exposure, and samples of cysts fixed for histological evaluation. In the second experiment (April, exposure temperature $11^{\circ} \mathrm{C}$ ), the mussels were fixed whole 4 mo after exposure and those with kidney cysts studied histologically. In each experiment 500 mussels were exposed (total 1000); the 500 control mussels were kept in clean brackish water in aquaria during the time of exposure.

Cages with the exposed or control mussels were fastened to an unused pier and anchored to the sea bottom. For histology the mussels were fixed in Helly's fixative and embedded in paraffin. $8 \mu \mathrm{m}$ thin sections were stained with Harris haematoxylin-eosin and 
Alcian-blue-PAS. Sections from 10 mussels were stained with Twort's Gram-method to detect any bacterial infection associated with cyst formation.

\section{RESULTS}

In the first and second experiment, cystic kidneys were found in 22 and $18 \%$ of the survivors, respectively ( 166 of 830 survivors). There were no cysts in control mussels. The cysts arose between mantle and gill at the posterior end of the mussel. They were thin-walled, round, brownish and collapsed easily; their size varied from barely visible to $1 \mathrm{~cm}$ (Fig. 1). Cysts were mostly single although some multiple cysts were found. The gills of affected mussels were deformed. The cyst wall was composed of 2 cell layers (Fig. 2A). The inner layer consisted of kidney epithelium, which at the stalk looked normal, but gradually changed to columnar epithelium. The outer layer consisted of columnar epithelium with mucous secretory cells, changing on top of the cyst to very flat squamous epithelium. The cysts were proliferative, both cell layers forming distensions and polypoid structures (Fig. 2B, C). The lumen between the 2 cell layers was filled with granular haemocytes. The cyst was filled with acellular material which gave a weak periodic acid-Schiff reaction. The cysts seemed to form as dilatations of the kidney tubules and were still partially connected to the rest of the kidney.

There was an acute inflammatory response associated with the cysts (Fig. 2A). No signs of bacterial infection could be detected on the slides.

\section{DISCUSSION}

Long-term exposure experiments with caged Mytilus edulis have been carried out for a number of years at the
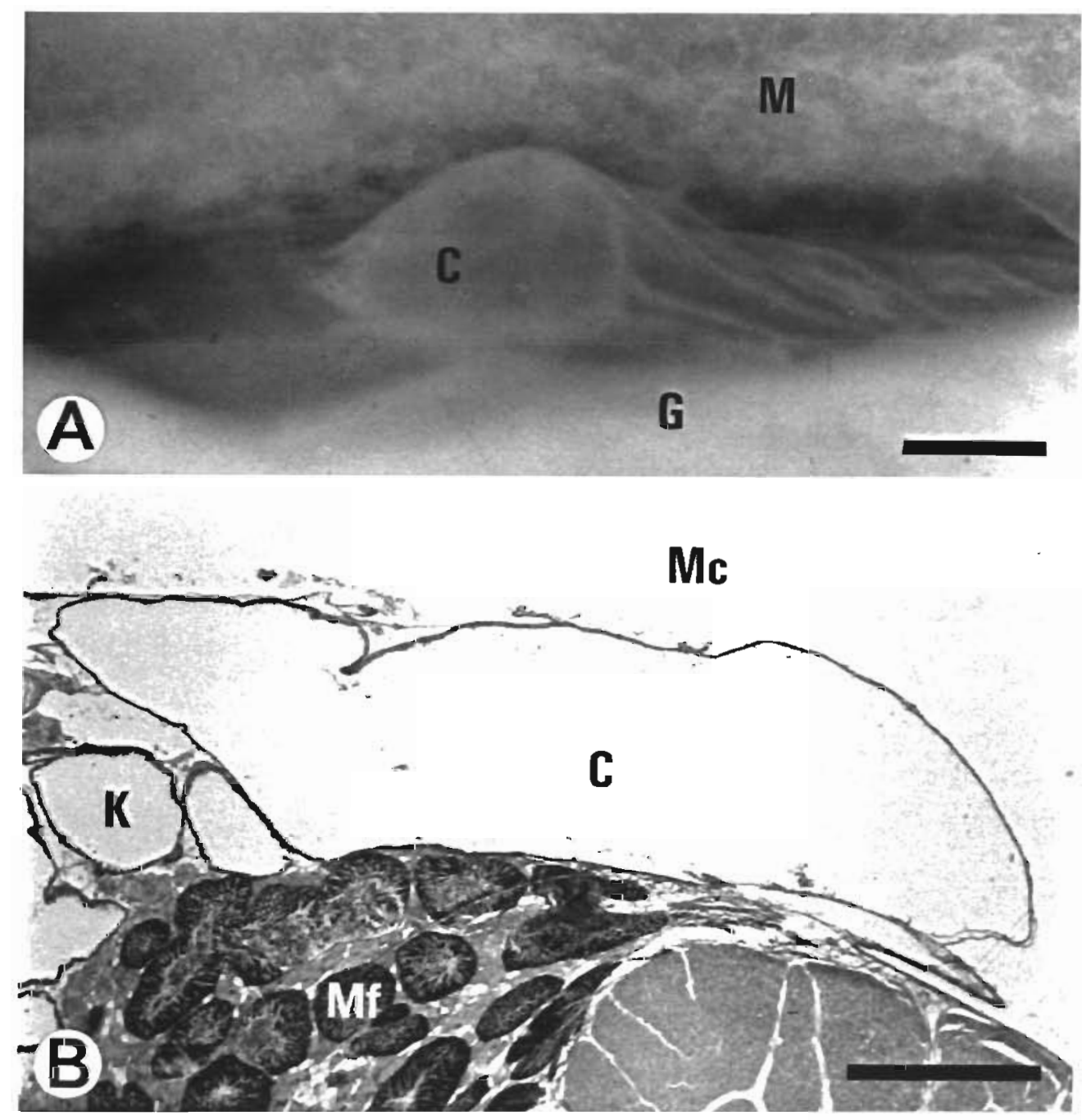

Fig. 1. Mytilus edulis. (A) Stereophotomicrograph of a renal cyst in an unstained total preparation; C: cyst; M: mantle; G: gills; scale bar $0.5 \mathrm{~cm}$. (B) Paraffin section of a mussel; $\mathrm{C}$ : cyst; Mf: male follicles; K: kidney tubules; Mc: mantle cavity; scale bar 1 mm 


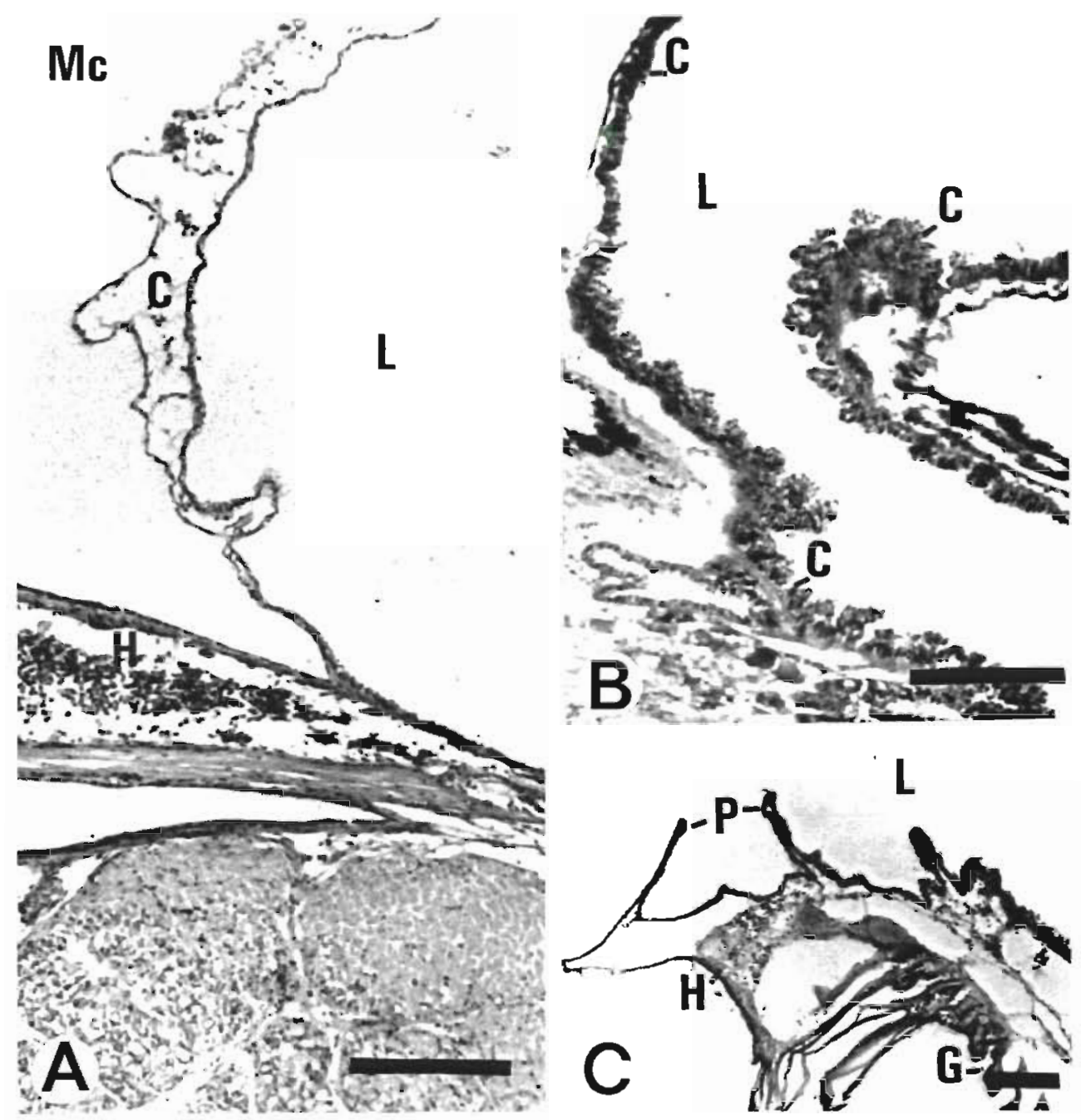

Fig. 2. Mytilus edulis. (A) Paraffin section of a mussel; C: cyst wall; Mc: mantle cavity; L: lumen of cyst; H: haemocytes, demonstrating an inflammatory response: scale bar $200 \mu \mathrm{m}$. (B) Infolded epithelium inside cyst; C: cyst wall; L: lumen of cyst; scale bar 200 um. (C) Polypoid epithelium inside cyst; P: Polyps; L: lumen of the cyst; G: gill arch; H: haemocytes; scale bar 200 um

Tvärminne Zoological Station in the Gulf of Finland (salinity $7 \%$ ). The $\mathrm{LC}_{50}$ value for copper in brackish water is 0.32 to $0.40 \mathrm{mg} \mathrm{l}^{-1}$ (Sunila 1981, Sunila \& Lindström 1985). Exposure to $0.2 \mathrm{mg} \mathrm{l}^{-1}$ of copper has been found to cause shell and gill deformities in longterm tests. In one study, shell deformities appeared in $46 \%$ of copper-exposed caged mussels, but were also common $(26 \%$ ) in control individuals (Sunila \& Lindström 1985). Of the copper-exposed mussels $\left(0.2 \mathrm{mg} \mathrm{l}^{-1}\right)$, $44 \%$ developed gill lesions. Deformed gills were low and had a folded edge. According to histological studies these abnormalities were due to fusions of the gill epithelia. These were classified as fusions of the frontal parts of the filaments, fusions of the abfrontal parts of the filaments or interlamellar fusions of the abfrontal parts of the filaments of opposite lamellae (Sunila 1986).

In the present study there was no evidence of bacterial infection or of chronic inflammation. There was, however, an acute inflammatory response between the cyst walls and in the tissues surrounding it. No sporozoan parasites were found. Cystic kidneys in the exposed mussels occurred concurrently with gill lesions. This correlation is not found in the field. Cysts are rare in the study area, only 1 mussel with a cyst having been found, but gill lesions are common in polluted areas (Sunila 1987).

Dobyan et al. (1981) induced cyst formation in rat kidney by cis platinum administration. The cysts were lined by simple squamous epithelium. Safouch et al. (1970) induced experimental cystic disease in rat kidney with diphenylamine. The cysts formed as dilatations of the kidney tubules and were lined with tubular epithelium. According to Gardner et al. (1976), cysts are the consequence of partial tubular obstruction and elevated intratubular pressure. Goodman et al. (1970) induced multiple cysts in rat kidney with nordihydroguaiaretic acid. The contents of small cysts were strongly PAS-positive but only slightly so in 
larger cysts. Cyst walls were composed of tubular epithelium and were thought to originate from tubular blockage.

Carone et al. (1974) induced cyst formation in rat kidney with diphenyl thiazole. No evidence of tubular obstruction was found, and the condition was considered to originate from alterations in the structure of the tubular basement membrane, which in the presence of a normal transtubular pressure gradient results in progressive tubular dilatation. Their results confirmed previous findings that cysts are not closed sacs but occur as tubular distensions with functioning nephrons, cell proliferation accompanying tubular enlargement.

There have been several reports of cystic enlargement of the kidneys of cyprinids. The aetiology is either the presence of a sporozoan parasite (Mitraspora cyprini) or unknown. Environmental pollution as a cause of polycystic kidneys in goldfish Carassius auratus has been suggested by Munkittrich et al. (1985). They found a prevalence of $6.3 \%$ (5 of 80 ) goldfish with cystic kidneys from a heavily polluted industrial bay.

Renal cysts in mussels have many features in common with vertebrate renal cysts despite major functional and anatomical differences in the organ. In the mussel kidney, the ultrafiltrate passes from the pericardial cavity into the renopericardial canal which opens by a convoluted ciliated funnel within the kidney lumen just above the excretory duct. According to Pirie \& George (1979), the fluid from the renopericardial canal may pass directly to the exterior without passing through the entire length of the kidney lumen. However, in this study, partial obstruction due to polyps caused dilatation of the distal tubules. This might originate from pressure caused by an inflow of ultrafiltrate. As a result, the tubular epithelium starts to proliferate, forming a large cyst which expands into the mantle cavity.

\section{LITERATURE CITED}

Carone, F. A., Rowland, R. G., Perlman, S. G., Ganote, C. E. (1974). The pathogenesis of drug-induced renal cystic disease. Kidney Int. 5: 411-421

Dobyan, D. C., Hill, D., Lewis, T., Bulger, R. E. (1981). Cyst formation in rat kidney induced by cis platinum administration. Lab. Invest. 45: 260-268

Gardner, K. D. Jr, Solomon, S., Fitzgerrec, W N., Evan. E. P. (1976). Function and structure in the diphenylamineexposed kidney. J. clin. Invest. 57: 796-806

George, S. G., Coombs, T L., Pirie, B. J. S. (1982). Characterization of metal-containing granules from the kidney of the common mussel, Mytilus edulis. Biochem. Biophys. Acta 716: $61-72$

Goodman, T., Grice, H. C., Becking, G. C., Salem, F. A. (1970). A cystic nephropathy induced by nordihydroguaiaretic acid in the rat. Lab. Invest. 23: 93-107

Munkattrıck, K. K., Moccia, R. D., Leatherland, J. F. (1985) Polycystic kidney disease in goldfish (Carassius auratus) from Hamilton Harbour, Lake Ontario, Canada. Vet. Pathol. 22: 232-237

Pirie, B. J. S., George, S. G. (1979). Ultrastructure of the heart and excretory system of Mytilus edulis (L.). J. mar. Biol. Ass. U. K. 59: 819-829

Safouch, M., Crocker, J. F. S., Vernier, R. L. (1970). Experimental cystic disease of the kidney: sequential, functional and morphological studies. Lab. Invest. 23: 392-400

Sunila, I. (1981). Toxicity of copper and cadmium to Mytilus edulis L. (Bivalvia) in brackish water. Annls Zool. fenn. 18: 213-223

Sunila, I., Lindström, R. (1985). Survival, growth and shell deformities of copper and cadmium-exposed mussels (Mytilus edulis L.) in brackish. water. Estuar. coast. Shelf Sci. 21. 555-565

Sunila, I. (1986). Chronic histopathological effects of shortterm copper and cadmium exposure on the gill of the mussel, Mytilus edulis. J. invert. Pathol. 47: 125-142

Sunila, I. (1987). Histopathology of mussels (Mytilus edulis L.) from the Tvärminne area, the Gulf of Finland (Baltic Sea). Annis Zool. fenn. 24: 55-69

Walsh, P. C., Gittes. R. F., Perlmutter, A. D., Stamey, T. A. (eds.) (1986). Campbell.'s urology. W B. Saunders Company, Philadelphia

Yevich, P. P. (1980). Comparative histophysiology of excretion in marne molluscs. Thalassia jugosl. 16: 399-403 